\title{
Developmental dyslexia: ERP correlates of anomalous phonological processing during spoken word recognition.
}

Citation for published version (APA):

Bonte, M. L., \& Blomert, L. P. M. (2004). Developmental dyslexia: ERP correlates of anomalous phonological processing during spoken word recognition. Cognitive Brain Research, 21(3), 360-376. https://doi.org/10.1016/j.cogbrainres.2004.06.010

Document status and date:

Published: 01/01/2004

DOI:

10.1016/j.cogbrainres.2004.06.010

Document Version:

Publisher's PDF, also known as Version of record

Document license:

Taverne

Please check the document version of this publication:

- A submitted manuscript is the version of the article upon submission and before peer-review. There can be important differences between the submitted version and the official published version of record.

People interested in the research are advised to contact the author for the final version of the publication, or visit the DOI to the publisher's website.

- The final author version and the galley proof are versions of the publication after peer review.

- The final published version features the final layout of the paper including the volume, issue and page numbers.

Link to publication

\footnotetext{
General rights rights.

- You may freely distribute the URL identifying the publication in the public portal. please follow below link for the End User Agreement:

www.umlib.nl/taverne-license

Take down policy

If you believe that this document breaches copyright please contact us at:

repository@maastrichtuniversity.nl

providing details and we will investigate your claim.
}

Copyright and moral rights for the publications made accessible in the public portal are retained by the authors and/or other copyright owners and it is a condition of accessing publications that users recognise and abide by the legal requirements associated with these

- Users may download and print one copy of any publication from the public portal for the purpose of private study or research.

- You may not further distribute the material or use it for any profit-making activity or commercial gain

If the publication is distributed under the terms of Article $25 \mathrm{fa}$ of the Dutch Copyright Act, indicated by the "Taverne" license above, 


\title{
Developmental dyslexia: ERP correlates of anomalous phonological processing during spoken word recognition
}

\author{
Milene L. Bonte*, Leo Blomert \\ Department of Cognitive Neuroscience, Faculty of Psychology, University of Maastricht, P.O. Box 616, 6200 MD Maastricht, The Netherlands
}

Accepted 22 June 2004

Available online 12 August 2004

\begin{abstract}
Ample evidence suggests that developmental dyslexia results from a phonological deficit that may not be reducible to a low-level auditory deficit. Yet, on-line phonological processing (in)capacities in dyslexics remain virtually unexplored, as studies have typically focused on either meta-phonological awareness tasks or, at the other extreme, basic perceptual tasks. The present study investigates event-related potential (ERP) correlates of implicit phonological processing during the recognition of spoken words in dyslexic and normally reading children (7-10 years). We examined general ERP morphology and alliteration priming effects on ERP measures in an auditory lexical decision task. Primes were words (Experiment 1) and non-words (Experiment 2). Alliteration priming effects suggested a distinct pattern of normal versus anomalous aspects of spoken word processing in dyslexic children. Whereas dyslexics showed deviant priming effects in earlier time windows encompassing the N1 and N2, later N400 priming effects were comparable to those of normal readers. The same pattern of results was also present in group comparisons of general ERP morphology. These findings suggest that dyslexics have selective processing anomalies at an earlier phonetic/phonological level, while processing at a later phonological/lexical level proceeds normally. In particular, our results indicate an anomalous contribution of phonological (word onset) information to the processing of spoken words, which may be related to time-course aspects of phonetic/phonological processing.
\end{abstract}

(C) 2004 Elsevier B.V. All rights reserved.

Theme: Disorders of the nervous system

Topic: Developmental disorders

Keywords: Developmental dyslexia; Auditory event-related potentials (ERPs); Phonological priming; Spoken word recognition; Phonological deficit theory

\section{Introduction}

The acquisition of reading is a complex cultural achievement that builds on primary spoken language skills [53]. In particular, the development of efficient processing and awareness of the sound structure of language, its phonological make-up, has been found to constitute a critical prerequisite for the acquisition of fluent reading [46]. Moreover, numerous studies indicate that the failure to adequately develop these phonological skills may underlie

* Corresponding author. Tel.: +31 43 3884036; fax: +31 433884125 .

E-mail address: m.bonte@psychology.unimaas.nl (M.L. Bonte). difficulties in reading and/or spelling such as experienced in developmental dyslexia [73].

Developmental dyslexia is a specific language-based disorder of constitutional origin characterized by difficulties in reading and/or spelling which are unexpected in relation to age and other cognitive abilities [63]. It affects a relatively large percentage of the population with prevalence estimates ranging from $3 \%$ to $10 \%$ [52]. A recent nationwide study of an elementary school population in The Netherlands estimated a prevalence of reading and/or spelling problems of $8.8 \%$, of which $3.6 \%$ were dyslexic [4]. Empirical evidence suggests that developmental dyslexia is associated with a phonological deficit [46]. Dyslexics perform below average on a large variety of 
experimental tasks which require phonological skills, like rhyme judgment, phoneme deletion or verbal short term memory tasks [73]. Moreover, during performance of such tasks, dyslexics show abnormal patterns of brain activation, with a typical disruption in left temporo-parietal regions as revealed by neuro-imaging studies, and various time-course differences as shown by event-related potential (ERP) and magneto-encephalographic (MEG) studies (for reviews, see Refs. [25,77]).

Yet, on-line phonological processing (in)capacities in dyslexics remain virtually unexplored, as studies have typically focused on either indirect meta-phonological awareness tasks like rhyme judgments or, at the other extreme, perceptual tasks involving the discrimination and categorization of speech sounds. Behavioral studies using the latter type of perceptual tasks reported poor categorical perception of phonemes at the onset of $\mathrm{CV}$ syllables in dyslexics (e.g., /ba/-/da/ [42,76]). Furthermore, ERP studies have indicated poor sensory change detection (as measured with the mismatch negativity [MMN]) to $\mathrm{CV}$ syllables in dyslexic adults [69] and children [68]. The observed categorical perception deficit has been suggested to result from poorly specified phonological representations $[42,73]$, or alternatively, an underlying auditory deficit related to the processing of short, acoustic transients $[62,74,76]$. Recent evidence suggests that low-level auditory perception deficits are only present in a subset of dyslexics $[33,60]$, and that if present, they may not typically reflect an impairment in the perception of rapidly presented acoustic information $[42,48,59,71]$. Moreover, as studies that reported categorical perception problems in dyslexics have typically used synthetic speech stimuli $[42,62,68,69]$, further studies are needed to examine whether these problems affect natural speech perception. Especially because in a recent study dyslexic children only showed categorical perception deficits for synthetic but not for natural speech stimuli [5]. Furthermore, a series of experiments on different levels of context effects in speech perception indicated that the quality of acoustic and phonetic representations used in the perception of natural speech may be similar in dyslexic and normally reading children [6]. These findings suggest that, even if difficulties in early acoustic and phonetic processing are present, they may not hamper on-line speech perception in dyslexics. Thus, it becomes interesting to investigate the quality and use of pre-lexical phonetic/ phonological representations necessary for lexical access [40]. Accordingly, the present study compares ERP correlates of implicit phonological processing of word onsets during the recognition of spoken words in dyslexic and normally reading children. In this way, we further investigate the hypothesis that the neurobiological impairment underlying developmental dyslexia affects the development of the phonological component of spoken language.

The recording of ERPs is one of the few techniques that is both usable with children and adequate for the investigation of on-line information processing in the brain on a millisecond basis [20]. In normally reading adults, ERPs have been an important tool in characterizing the time course of neural systems involved in different aspects of language processing including those related to the processing of phonological, semantic and syntactic information [35]. An ERP component typically elicited during the processing of written or spoken words is the N400, a sustained negativity peaking around $400 \mathrm{~ms}$ [35]. The amplitude of the N400 appears to reflect the extent to which a word is semantically primed, i.e., a word that is semantically expected elicits a reduced N400. Similarly, phonological priming, i.e., alliteration (shared word onsets) or rhyme has been found to reduce the amplitude of an N400 waveform $[17,54,57,64]$. In the auditory modality, such phonological N400 effects start earlier for alliteration than for rhyming, suggesting that the effect may follow the temporal dynamics of spoken word processing [56]. Whereas semantic N400 effects persist during word processing tasks that discourage semantic processing, phonological N400 effects are less robust and mainly occur in experiments that encourage explicit phonological processing [54].

ERP studies in adults further suggest that during auditory sentence processing, phonological expectations may modulate a negativity at a latency of $200-300 \mathrm{~ms}$ preceding the N400 (e.g., Refs. $[14,26,83]$ ). Similar to the phonological N400 effect, this negativity, labeled, e.g., phonological mismatch negativity (PMN), shows an increased amplitude when words/non-words do not match a phonological expectation. Negativities like the PMN have been interpreted to reflect phonological processing of word onsets and/or the initial activation of lexical candidates. More specifically, Newman et al. [47] suggested that the PMN may reflect a pre-lexical stage of spoken word recognition involving the translation of acoustic input into pre-lexical phonological representations necessary for lexical access. To our knowledge, there are no previous reports of PMN effects in children.

Developmental ERP studies with normal readers have reported adult-like phonological N400 effects for auditory and visual rhyming in adolescents [39], and even in children as young as 7 years $[13,24]$. In contrast, dyslexic adolescents have been reported to show a deviant phonological N400 effect for rhyming words in visual studies (e.g., Ref. [1]), and to show abnormal phonological N400 effects with auditory rhyming [39] and auditory alliteration [38]. These deviant phonological N400 effects in dyslexics may reflect ERP correlates of their difficulties with phonological awareness tasks. However, the complex task requirements of these explicit phonological awareness tasks may alter the way in which phonological information is usually processed. It may even be questioned if the usual phonological awareness task taps phonological processing aspects of the ongoing word recognition process. That is, the defining element of a phonological awareness task (phoneme monitoring, deletion or insertion) may be performed 
after, rather than prior to, the point at which a word is recognized (e.g., Ref. [78]). Furthermore, these tasks require a set of processes over and above the word recognition processes; for example, high attention and memory loads [58]. As a consequence, it is hard to disentangle which of these processes is instrumental in the typically reported poor performance and which processes contribute to the reported deviant N400 effects in dyslexics.

The present study addresses the question whether dyslexic children show differences in phonological priming effects on ERP measures when phonological monitoring or awareness is not an explicit task requirement. We investigate alliteration priming effects on ERPs elicited by words and non-words in a lexical decision task. In a previous study this paradigm proved to be a valuable method for the investigation of normal developmental changes in implicit phonological processing during the recognition of spoken words [7]. In that study, we examined adults and children of different age groups (pre-schoolers: $5 / 6$ years and beginning readers: 7/8 years) in two experiments, with word primes (Experiment 1) and non-word primes (Experiment 2). We were interested in these age groups because during early school years the lexical system may show substantial restructuring of phonological processing and representation, especially at the level of word onsets [7,41]. In addition to a general decrease of ERP latency with age, our data showed substantial developmental changes in the negativities elicited in the latency range of the adult N1-P2 complex. The corresponding negativities, which we labeled as $\mathrm{N}_{200}$ (pre-schoolers) and N1-N2 (beginning readers) most likely do not simply reflect delayed equivalents of the same components in adults and show complex structural and functional changes with age $[7,8,12,32]$. Prominent phonological priming effects were an enhanced N400 amplitude due to alliterating word primes in beginning readers and reduced N400 amplitudes due to alliterating non-word primes in all age groups. The N400 amplitude reductions are similar to the phonological N400 effects reported in the literature $[13,56]$ and may analogously indicate less effortful neural processing in case of alliteration with non-word primes. In contrast, the N400 amplitude enhancement as uniquely shown by beginning readers may reflect more effortful neural processing in case of alliterating word pairs, possibly reflecting a neural correlate of the common finding in psycholinguistic research that words sharing onsets compete for activation during spoken word recognition (see Ref. [7]). Under the same experimental conditions alliteration did not elicit an N400 enhancement in adults and pre-schoolers. In adults, this was presumably due to fast and automatized lexical processing of word primes. In preschoolers, on the other hand, spoken word recognition may not yet capitalize on word onset information (see Refs. $[7,41]$ ). Priming further led to opposite early effects with word primes (N1/ $\mathrm{N}_{200}$ reduction) vs. non-word primes (P1/ N1 enhancement) in all groups (see Ref. [13] for phonological priming effects at a similar latency). These opposite priming effects shown in all age groups may suggest that the processing of word onsets was differentially affected by word vs. non-word primes. Overall, the distinct pattern of priming effects obtained in the three age groups supports the view that during early school years the spoken word recognition system undergoes substantial restructuring at the level of phonological processing and representation as a result of both vocabulary growth and the acquisition of reading [7] (see also Refs. [31,41]). Most importantly, our study revealed particularly strong alliteration priming effects in beginning readers, as compared to both other age groups. This indicates distinct processing of word-initial phonological information in children around 8 years old. Here we use the same experimental design to investigate ERP correlates of implicit phonological processing in dyslexic children in the same age range and compare them to the results previously obtained with normally reading children.

The presence or absence of normal alliteration priming effects in dyslexic children is expected to differentiate underlying difficulties at distinct levels of processing. First, deviant early, N1/N2, priming effects may indicate processing anomalies at a phonetic/phonological level. Second, deviant N400 priming effects may indicate processing abnormalities at a later phonological/lexical level. Dependent on the experimental task used, dyslexics have been reported to show abnormalities in both the auditory N1 (e.g., Refs. [27,28]) and the auditory N400 time-window [36-39]. Finally, deviant ERP latency and morphology in response to words may indicate anomalies in the speed and efficiency of spoken word recognition in dyslexic children.

\section{Materials and methods}

\subsection{Subjects}

Twenty-nine subjects (15 dyslexics, 14 normal readers) participated in Experiment 1 and 27 subjects (14 dyslexics, 13 normal readers) in Experiment 2. In Experiment 1, data of 24 subjects were included in the analysis, i.e., 12 dyslexics ( 6 female, mean age: $8.8 \pm 0.70)$ and 12 normal readers ( 9 female, mean age: $8.0 \pm 0.64$ ). In Experiment 2, data of 23 subjects were included in the analysis, i.e., 12 dyslexics (6 female, mean age: $8.8 \pm 0.65$ ) and 11 normal readers ( 8 female, mean age: $8.0 \pm 0.53$ ). In total, data of five dyslexics and four normal readers were discarded, due to excessive movement artifacts or an incidental technical problem. Eight normal readers and 10 dyslexics participated in both experiments.

All children were given a present for participation. Informed consent was obtained from the parents of the children. Approval for the study was granted by the Ethical Committee of the Faculty of Psychology at the University of Maastricht. Dyslexic children were recruited from the Regional Institute of Dyslexia (RID), which is 
one of the major specialized dyslexia institutes in The Netherlands. Prior to the present study, they were diagnosed as dyslexic after an extensive cognitive psycho-diagnostic procedure by the RID. This testing procedure included an intelligence test (WISC-R, Dutch version [84]), the results of which were used in the present study. Normal readers were recruited from local schools, and were judged by their school teachers to be average or above average in academic achievement.

Subject characteristics and results of behavioral tests are given in Table 1. All subjects were native Dutch speakers. With the exception of one of the dyslexics, all subjects were right-handed, as assessed with Annett's Handedness Questionnaire [2]. All parents of children reported the absence of any history of hearing loss. Dyslexic children were on average 8 months older than normal readers. All subjects had normal or above normal IQ scores, as measured with the Raven Coloured Progressive Matrices [61] in normal readers, and the WISC-R [84] in dyslexics. Both dyslexics and normal readers performed standardized language tests, including two reading tests, the Een-minuut-leestest (1-min reading test [10]) and a non-word reading test [82], a passive vocabulary test [3] and, additionally, an unpublished phoneme-deletion task (devised by the RID). The phoneme deletion test asks children to delete the first phoneme of a spoken word and pronounce the remaining word. On each of the language tests, dyslexics performed significantly worse than normal readers, who scored at an age-appropriate level. Performance on the reading tests showed that the reading level of the dyslexic group lagged 1.5-2 years behind. Moreover, dyslexics per-

Table 1

Descriptive data for normal readers and dyslexics

\begin{tabular}{|c|c|c|c|}
\hline & $\begin{array}{l}\text { Normal } \\
\text { readers }(n=15)\end{array}$ & $\begin{array}{l}\text { Dyslexics } \\
(n=14)\end{array}$ & Differences \\
\hline Age (years, months) & $\begin{array}{l}8.2 \\
(7.5-9.4)\end{array}$ & $\begin{array}{l}8.10 \\
(7.9-10.0)\end{array}$ & $\begin{array}{l}t=-3.0 \\
P=0.005\end{array}$ \\
\hline IQ (min-max) & $95-125$ & $99-123$ & $\begin{array}{l}t=1.7 \\
P=\text { n.s. }\end{array}$ \\
\hline Word reading $^{\mathrm{a}}$ & $6.7(1.2)$ & $2.5(1.7)$ & $\begin{array}{l}t=7.9 \\
P=0.000\end{array}$ \\
\hline Word reading $^{\mathrm{b}}$ & $55(8)$ & $38(12)$ & $\begin{array}{l}t=4.5 \\
P=0.000\end{array}$ \\
\hline Non-word reading $^{\mathrm{a}}$ & $6.7(1.2)$ & $3.2(1.3)$ & $\begin{array}{l}t=7.7 \\
P=0.000\end{array}$ \\
\hline Non-word reading ${ }^{\mathrm{b}}$ & $47(9)$ & $30(12)$ & $\begin{array}{l}t=4.2, \\
P=0.000\end{array}$ \\
\hline Passive vocabulary $^{\mathrm{a}}$ & $6.8(2.0)$ & $2.8(2.7)$ & $\begin{array}{l}t=4.6 \\
P=0.000\end{array}$ \\
\hline Passive vocabulary ${ }^{\mathrm{b}}$ & $43(5)$ & $37(9)$ & $\begin{array}{l}t=2.1 \\
P<0.05\end{array}$ \\
\hline Phoneme deletion $^{\mathrm{c}}$ & $95 \%(5 \%)$ & $83 \%(13 \%)$ & $\begin{array}{l}t=3.1 \\
P<0.005\end{array}$ \\
\hline
\end{tabular}

IQ scores (range) and performance on language tests (mean (S.D.)).

a Age-appropriate norms (standardized scale, mean=5, S.D.=2).

b Absolute values (number of correct items).

c Percentage correct, $\max =28$ items. formed worse than normal readers even when ageappropriate norms were disregarded and absolute performance was compared. Performance on the phoneme deletion test showed that all dyslexics suffered from phonological problems. It is important to note that although the groups differed on the passive vocabulary test, it is unlikely that it biased our results, as the words used in the present experiments were all simple words with an age of acquisition of 6 years or earlier (see below).

\subsection{Materials}

Stimuli were mono-morphemic bisyllabic Dutch words and non-words, all with a consonant onset. Non-words were created from words by changing one or two phonemes according to Dutch phonotactic rules. Words were selected using estimates of age of acquisition (AOA) rather than adult frequency ratings. The choice of this selection criterion was indicated by a recent study in which AOA was shown to be a more sensitive measure of lexical familiarity-than either word frequency or neighborhood density - for making developmental comparisons of spoken word recognition in children [21]. Our AOA criterion was 6 years or earlier. Estimates of AOA were based on two published ratings: (1) vocabulary estimates of 6 year olds [67], (2) AOA of Dutch words [22] and a subsequent student/parent familiarity rating of the selected words.

The stimuli were spoken by a female native Dutch speaker and recorded on a DAT recorder at a sampling rate of $44.01 \mathrm{kHz}$. Word onsets and offsets were determined using a speech waveform editor. The digitized stimuli were $\mathrm{D} / \mathrm{A}$ converted with an 8-bit resolution, band-pass filtered $(30 \mathrm{~Hz}-10.6 \mathrm{kHz})$ and re-sampled at $22.05 \mathrm{kHz}$. The mean acoustical duration of word primes was $596 \mathrm{~ms}$ (range: 413-819), non-word primes 619 ms (range: 409-796), alliterating word targets $576 \mathrm{~ms}$ (range: 387-789), unrelated word targets $603 \mathrm{~ms}$ (range: 464-760) alliterating non-word targets $626 \mathrm{~ms}$ (range: 433-864) and unrelated non-word targets $592 \mathrm{~ms}$ (range: 353-786). Statistical comparison of prime or target lengths only showed significant differences between unrelated and related nonword targets $(P<0.025)$.

\subsection{Design}

In both experiments, we used an auditory lexical decision task in combination with alliteration priming. In Experiment 1, primes were words; in Experiment 2, primes were non-words. Prime-target pairs were either phonologically unrelated (unrelated) or shared the initial two phonemes (alliterating) (see Fig. 1a/b). In both experiments, the same set of targets was used: 116 words and 116 non-words. Within each experiment, primes were presented twice, in separate blocks, once in combination 


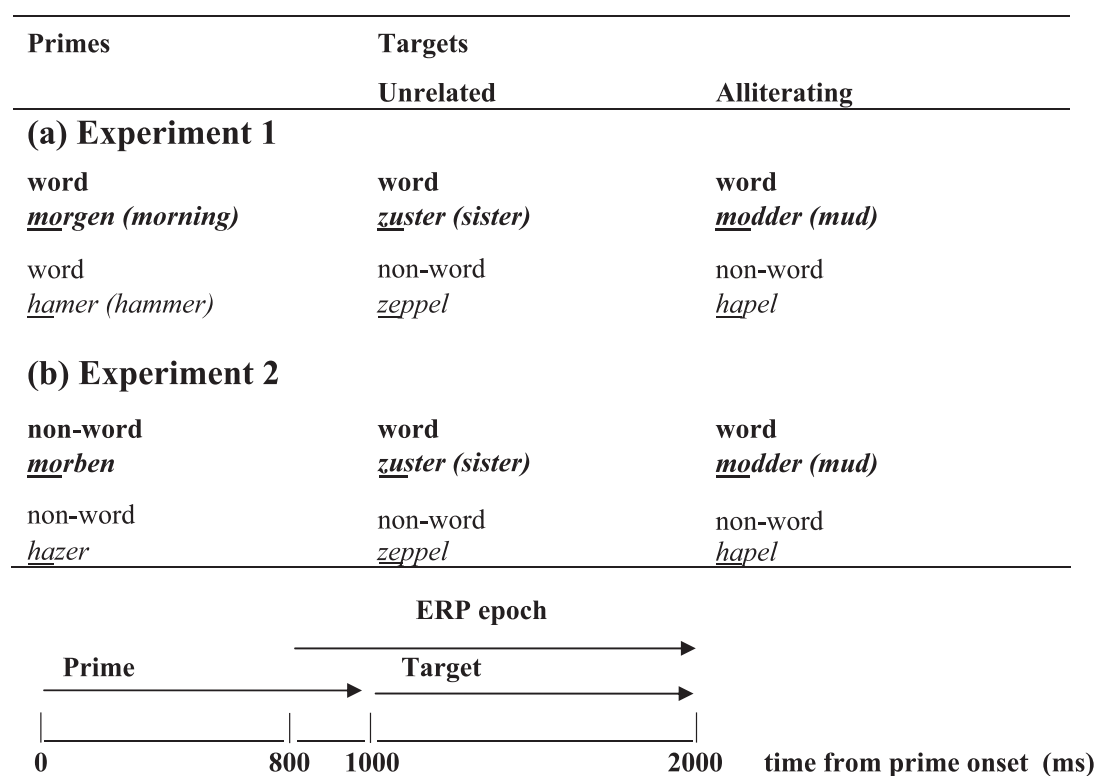

Fig. 1. Design and example stimuli of Experiment 1 (a) and Experiment 2 (b). Prime-target pairs were either phonologically unrelated (unrelated) or shared the initial two phonemes (alliterating).

with an unrelated and once with an alliterating word or non-word target. In this way, targets were never repeated within the same experiment. Prime and target were never semantically related and had the same pattern of syllable stress.

\subsection{Procedure}

Subjects were tested individually in a sound-attenuating and electrically shielded room. They were seated in a comfortable chair in front of a computer monitor. Before the experiment started, subjects performed a separate 5 min block of practice trials with stimuli that did not occur in the experiment. Stimuli were presented binaurally through loudspeakers at $65 \mathrm{~dB}$ SPL. Subjects were instructed not to move their eyes and sit quietly especially when a fixation cross was present. Each trial started with a fixation cross which remained on the screen until the end of the trial. At a variable interval (400-1000 ms), after appearance of the fixation cross, the prime was presented. Prime-target stimulus onset asynchrony (SOA) was $1 \mathrm{~s}$. Maximum response time was set at $3000 \mathrm{~ms}$. Upon the response of the subject, a new trial started after an inter trial interval of $2000 \mathrm{~ms}$. Subjects were told to ignore the primes, attend carefully to the targets and press the right button in case of real words and the left button in case of non-words. Both speed and accuracy were encouraged. Cartoons of a blue thumb up (near right button) and a red thumb down (near left button) were used to prevent confusion of response hands. Children were given a short break every 20 trials. Both experiments consisted of 12 blocks; after the first 6 blocks, there was a longer break. Between subjects, we varied the order in which Experiments 1 and 2 were performed. Within subjects, there was a break of at least a week (and maximally 3 months) between the two experiments.

\subsection{EEG recording and data analysis}

Mean reaction times (RT) and error percentages were tested separately for word and non-word targets using an analysis of variance for repeated measures with overlap (alliterating vs. unrelated) as within, and group as between subjects factor. Group differences were further assessed with two-tailed independent samples $t$-tests.

EEG data were recorded from 29 electrodes (Extended international 10-20 system [49]): FP1/2, F7/8, F3/4, Fz, FT8/ 7, FC3/4, FCz, T3/4, C3/4, Cz, TP7/8, CP3/4, T5/6, P3/4, Pz, $\mathrm{O} 1 / 2$, Oz. Blinks and vertical eye movements were monitored with electrodes placed at the sub- and supra-orbital ridge of the left eye. Lateral eye movements were monitored by a bipolar montage using two electrodes placed on the right and left external canthus. The effects of blink artifacts were corrected [70]. All electrode impedance levels (EEG and EOG) were kept below $5 \mathrm{k} \Omega$. Electrophysiological signals were amplified with a band-pass filter of $0.01-50 \mathrm{~Hz}$ and digitized at a rate of $250 \mathrm{~Hz}$. EEG signals were recorded with a left mastoid reference and were offline re-referenced to the average of the right and left mastoid. Epochs of $1200 \mathrm{~ms}$, -200 to $1000 \mathrm{~ms}$ relative to target onset, were created from the continuous EEG data. Only trials with correct responses were analyzed. Data were baseline corrected to a $100-\mathrm{ms}$ prestimulus interval, $1-30-\mathrm{Hz}$ bandpass filtered and trials containing data exceeding a maximum voltage criterion of $\pm 100 \mu \mathrm{V}$ were rejected (automatic artifact rejection procedure, Neuroscan software [Neuroscan Labs, El Paso, TX]). The averages of all subjects, with the exception of the averages to non-word targets in one of the dyslexics, met our 
rejection criterion of $30 \%$, corresponding to the inclusion of at least 40 trials per condition. In Experiment 1, the mean (range) number of the accepted epochs in the grand averages for alliterating and unrelated word and non-word targets were 52 (45-57), 52 (49-55), 51 (46-57) and 52 (47-58) in normal readers, and 52 (43-56), 51 (44-57), 50 (40-56) and 49 (39$54)$ in dyslexics. In Experiment 2, the mean (range) number of the accepted epochs were 52 (42-57), 51 (43-56), 51 (40$57)$ and 51 (41-58) in normal readers, and 51 (43-58), 51 (42-56), 51 (45-56) and 48 (39-53) in dyslexics.

Experimental ERP effects were assessed by calculating mean amplitude values in time windows corresponding to prominent components in the ERP grand averages. The two negativities preceding the N400 were labeled N1 and $\mathrm{N} 2$. It should be noted that our ERP labels were meant as notifications, and refer to, e.g., a first (N1) and a second (N2) negativity, without assuming exact equivalence with adult components with the same names. We used different time windows to assess $\mathrm{N} 1$ effects at central versus lateral electrodes, as the peaks measured at these sites differed in latency and duration (see Results). Two consecutive 200$\mathrm{ms}$ windows were selected to assess early versus late phonological N400 effects. We used a single N2 window because this led to the same results as the use of two N2 windows. The resulting time windows were as follows: P1: $80-120 \mathrm{~ms}$, central N1: $120-170 \mathrm{~ms}$, lateral N1: 140-240, N2: $250-350 \mathrm{~ms}$ and N400a: $400-600 \mathrm{~ms}$, N400b: $600-800 \mathrm{~ms}$. Analyses of variance for repeated measures were carried out on mean amplitudes for word and non-word targets with overlap (unrelated vs. alliterating) and electrode as within subject factors and group as between subjects factor. For further analyses, we selected electrodes in which the ERP components are most frequently reported to occur, as we did not investigate underlying sources or topographical differences between groups. This selection was further justified by visual inspection of our data (see Figs. 2-6). Thus, as these ERP components are typically reported for vertex and fronto-central sites (e.g., Refs. [72,75]), P1, N1 and N2 effects were tested on $\mathrm{Fz}, \mathrm{FCz}$ and $\mathrm{Cz}$. Because the $\mathrm{N} 1$ also has a clear temporal component (e.g., Refs. [9,32]), we additionally tested N1 effects at T3 and T4. Because previous literature indicated a more posterior and lateral predominance for the phonological N400 effect (e.g., Refs. [13,56]), Fz, Cz, Pz, T3 and T4 were included when testing priming effects in the N400 time windows. The Greenhouse-Geisser correction was applied to repeated measures variables with more than two levels and is reported as corrected $p$ ( $p_{\text {cor }}$ ).

Dyslexic children have been reported to show anomalies in overall amplitude and latency measures of ERP/MEG components (e.g., Refs. [28,29]). To assess such differences, we performed additional planned comparisons (independent samples two-tailed $t$-tests) on ERP peak latencies and mean ERP amplitudes of average responses to word targets (collapsed over both experiments).

\section{Results}

\subsection{General pattern of ERPs elicited by word targets}

We investigated the general morphology of ERPs during word recognition by averaging responses to word
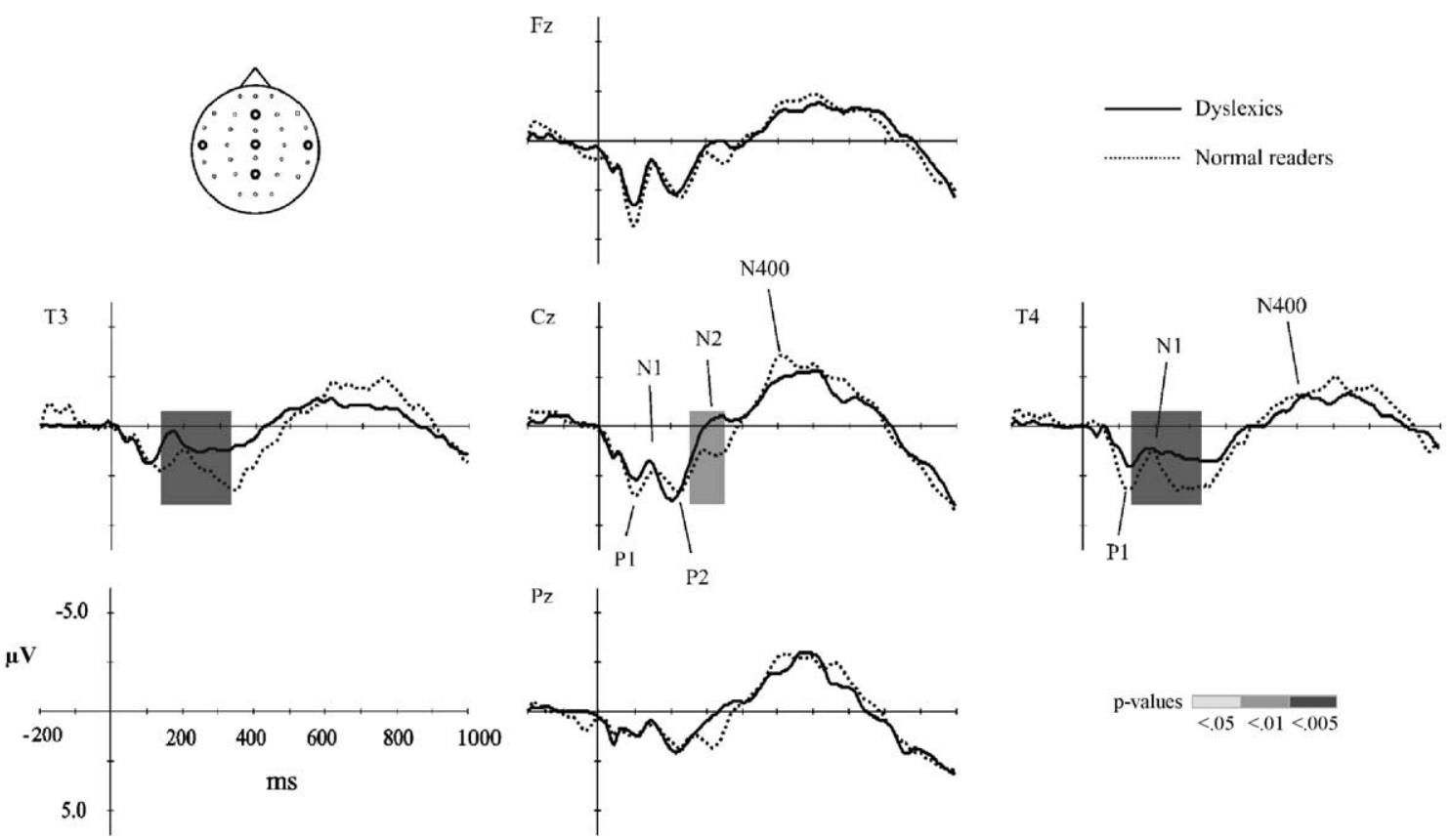

Fig. 2. Grand average ERP waveforms of word targets (collapsed over Experiments 1 and 2) for midline (Fz, Cz, Pz), left (T3) and right (T4) temporal electrodes for normal readers and dyslexics. 
targets from Experiments 1 and 2 (see Fig. 2). In both dyslexics and normal readers, word targets elicited a P1N1-P2-N2-N400 pattern at central electrodes and a P1N1-N400 pattern at lateral electrodes. None of these ERPs showed significant group differences in latency. However, ERP amplitudes and peak morphology showed significant group differences in the $\mathrm{N} 1$ and $\mathrm{N} 2$ windows. First, in the time window encompassing the lateral N1 (110-310 ms), mean ERP amplitude was significantly smaller for dyslexics as compared to normal readers at electrodes T3 $\left(t_{16}=3.3, P<0.005\right)$ and T4 $\left(t_{16}=4.5\right.$, $P=0.000)$. Second, at central electrodes, dyslexics showed a relatively broad N2 peak with an increased amplitude, leading to a significant group difference in mean N2 amplitude at $\mathrm{Cz}\left(t_{16}=3.1, P<0.01\right)$. There were no other significant differences between dyslexics and normal readers.

\subsection{Experiment 1: word primes}

In the first experiment, we investigated whether ERP data of dyslexic children indicate anomalies in the processing of phonetic/phonological representations during spoken word recognition [40]. Children performed a lexical decision task to word/non-word targets which were preceded by unrelated or alliterating word primes (Fig. 1a). Alliteration priming effects were expected to result from pre-lexical and/or lexical phonological processing as word primes involve both levels of processing.

\subsubsection{Behavioral measures}

Behavioral results and t-statistics for group comparisons are given in Table 2.

3.2.1.1. Reaction times. Mean RT for alliterating word targets was $1386 \mathrm{~ms}$ and for unrelated word targets 1351 ms. This overall slower RT to alliterating as compared to unrelated word targets led to a main effect of overlap
$\left(F_{1,22}=5.1, P<0.05\right)$. There were no group differences for RTs.

3.2.1.2. Error rates. Both normal readers and dyslexics performed the task accurately with mean error rates of $9 \%$ or lower. Error rates for word targets did not show significant effects of overlap or differences between groups. Error rates for non-word targets also did not show effects of overlap, but dyslexics had a significantly higher error rate than normal readers as indicated by a main effect of group $\left(F_{1,22}=17.2, P=0.00\right)$.

\subsubsection{Phonological priming effects: word targets}

ERP responses to alliterating and unrelated word targets are given in Fig. 3. A comparison of unrelated vs. alliterating word targets led to a significant main effect of overlap $\left(F_{1,22}=4.9, P<0.05\right)$ and a significant overlap*group interaction $\left(F_{1,22}=5.8, P=0.025\right)$ for the central N1. Whereas dyslexics did not show any significant effect of phonological priming $\left(F_{1,11}=0.015\right.$, n.s. $)$, normal readers showed a significant priming effect, i.e., alliterating word targets elicited a reduced N1 response as compared to unrelated word targets $\left(F_{1,11}=12.3, P=0.005\right)$. There were no significant priming effects in the $\mathrm{N} 1$ window at lateral electrode sites, nor in the N2 window at central electrodes.

As for the N400 time windows, both dyslexics and normal readers showed an enhanced N400 amplitude in response to alliterating as compared to unrelated word targets, leading to a significant main effect of overlap in the N400b window $\left(F_{1,22}=8.3, P<0.01\right)$ and no significant overlap*group interaction.

\subsubsection{Phonological priming effects: non-word targets}

ERP responses to non-word targets are given in Fig. 4. In both subject groups, ERP morphology in response to nonword targets was comparable to that elicited by word targets. Overall the ERP signal to non-word targets showed a relatively large variability. The phonological priming effect

Table 2

Mean (S.E.M.) of RTs in milliseconds and error percentages for normal readers and dyslexics in Experiment 1

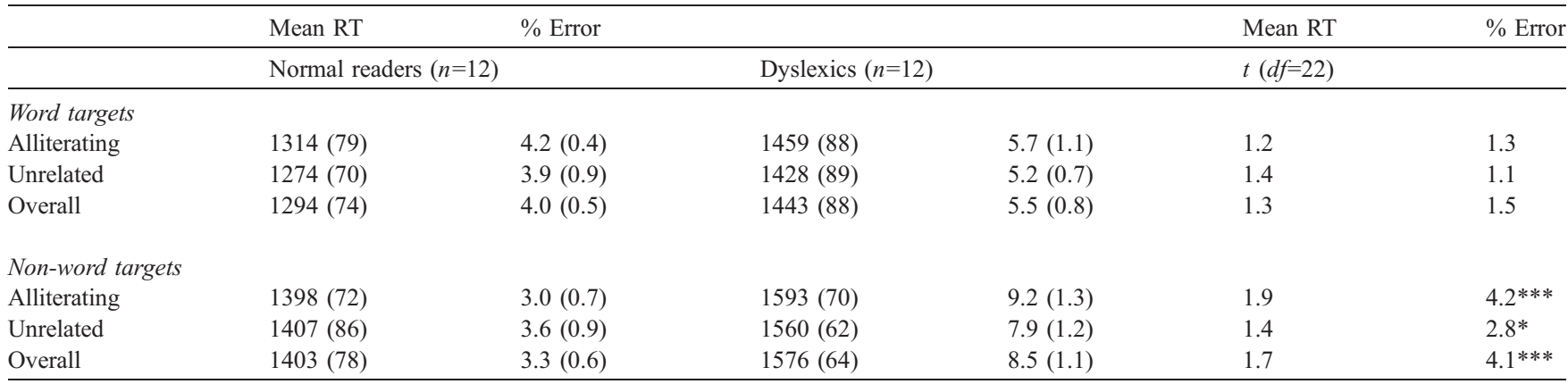

$* P<0.05$.

$* * * P<0.005$. 


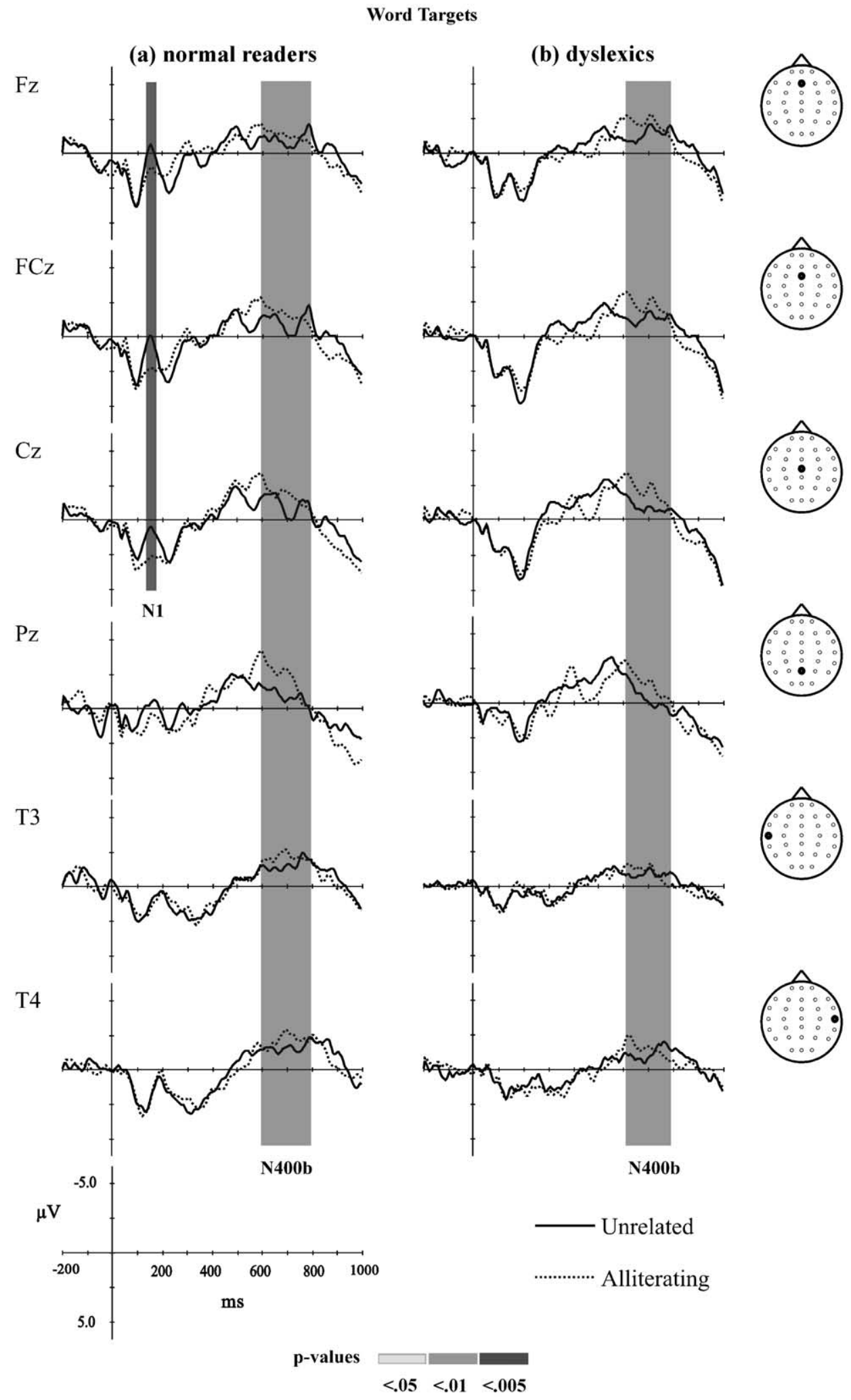

Fig. 3. Grand average ERP waveforms elicited by word targets in Experiment 1 (word primes), in (a) normal readers and (b) dyslexics at midline (Fz, FCz, Cz, $\mathrm{Pz}$ ), left (T3) and right (T4) temporal electrodes. 
in the N400b window, as shown to word targets by normal readers and dyslexics, was not present with non-word targets, neither was the N1 effect as shown by normal readers.
With non-word targets, alliteration led to comparable effects in dyslexics and normal readers as indicated by main effects of overlap in the N2 window $\left(F_{1,22}=11.9, P<0.005\right)$

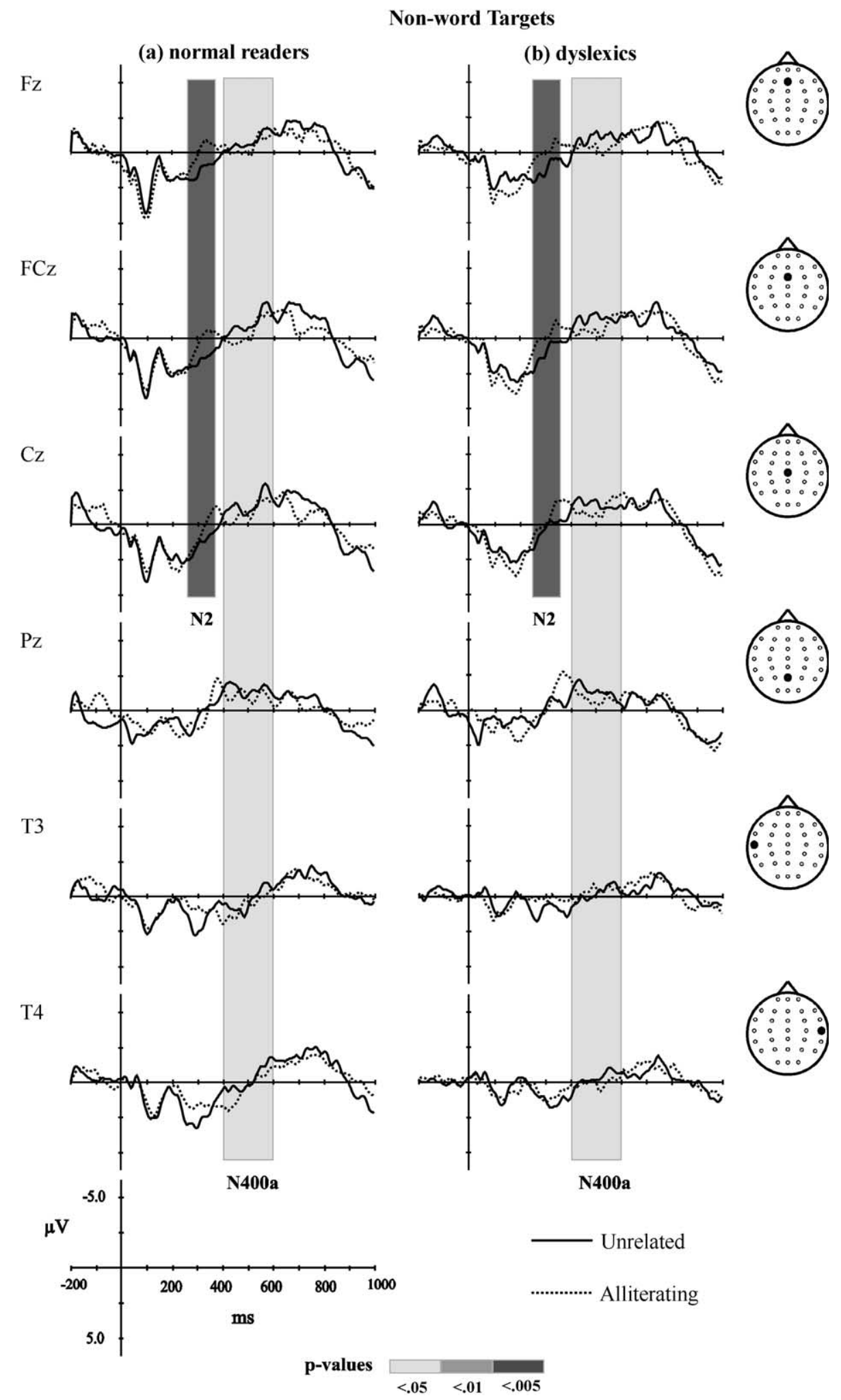

Fig. 4. Grand average ERP waveforms elicited by non-word targets in Experiment 1 (word primes), in (a) normal readers and (b) dyslexics at midline (Fz, FCz, $\mathrm{Cz}, \mathrm{Pz}$ ), left (T3) and right (T4) temporal electrodes. 
and the N400a window $\left(F_{1,22}=6.2, P<0.025\right)$. In both groups, alliterating non-word targets elicited an enhanced N2 amplitude and a reduced N400 amplitude as compared to unrelated non-word targets. A significant overlap*group interaction in the N400b window $\left(F_{1,22}=4.2, P=0.05\right)$, suggested a different priming effect in normal readers and dyslexics. Within groups, overlap led to a trend in normal readers $\left(F_{1,11}=4.6, P=0.06\right)$ and no effect in dyslexics $\left(F_{1,11}=1.7\right.$, n.s. $)$.

\subsection{Experiment 2: non-word primes}

In the second experiment, we investigated whether dyslexic children show anomalies in alliteration priming effects resulting from pre-lexical phonological processing. In this experiment, children performed the same lexical decision task, but primes were alliterating or unrelated non-words instead of words (see Fig. 1b). Alliteration priming effects were expected to result from pre-lexical processing as non-word primes do not have a lexical representation.

\subsubsection{Behavioral measures}

Behavioral results and $t$-statistics for group comparisons are given in Table 3.

3.3.1.1. Reaction times. Mean RT for alliterating word targets was $1361 \mathrm{~ms}$ and for unrelated word targets 1354 ms. There were no significant effects of overlap or differences between groups for RTs.

3.3.1.2. Error rates. Both normal readers and dyslexics performed the task accurately with mean error rates of $10 \%$ or lower. Error rates for word targets did not show significant effects of overlap or differences between groups. Error rates for non-word targets showed significant main effects of overlap $\left(F_{1,21}=6.1, P<0.025\right)$ and group $\left(F_{1,21}=6.0, \quad P<0.025\right)$ and an overlap*group interaction $\left(F_{1,21}=5.2, P<0.05\right)$. Whereas normal readers did not show significant effects of overlap, dyslexics made significantly more errors for alliterating as compared to unrelated non-word targets $\left(F_{1,11}=8.0\right.$, $P<0.025)$. Dyslexics further showed a significantly higher error rate than normal readers for alliterating $\left(t_{21}=3.0\right.$, $P<0.01)$, but not for unrelated $\left(t_{21}=1.6\right.$, n.s. $)$ non-word targets.

\subsubsection{Phonological priming effects: word targets}

ERP responses to alliterating and unrelated word targets are given in Fig. 5. Phonological priming led to a main effect of overlap $\left(F_{1,21}=19.5, P=0.000\right)$ and a significant overlap*group interaction $\left(F_{1,21}=4.3, P=0.05\right)$. Whereas dyslexics only showed a trend towards a priming effect $\left(F_{1,11}=3.1, P=0.10\right)$, normal readers showed a significant priming effect, i.e., alliterating word targets elicited an enhanced N1 response as compared to unrelated word targets $\left(F_{1,10}=18.5, P<0.005\right)$.

At lateral sites, there was a main effect of overlap for the N1 $\left(F_{1,21}=7.6, P<0.025\right)$ and no significant interaction effects, indicating a small enhancement of the N1 amplitude for alliterating as compared to unrelated word targets in both normal readers and dyslexics. In later time windows, there was a significant reduction in the N400a amplitude elicited by alliterating as compared to unrelated word targets as indicated by a main effect of overlap $\left(F_{1,21}=10.0, P=0.005\right)$.

\subsubsection{Phonological priming effects: non-word targets}

ERP responses to non-word targets are given in Fig. 6. Like in Experiment 1, ERP morphology in response to nonword targets was comparable to that elicited by word targets, but showed more variability. There were no significant priming effects in the $\mathrm{N} 1$ window at central electrode sites. However, in both groups, alliteration led to an enhanced $\mathrm{N} 1$ response at lateral electrodes and an enhanced N2 response at central electrodes, as shown by

Table 3

Mean (S.E.M.) of RTs in milliseconds and error percentages for normal readers and dyslexics in Experiment 2

\begin{tabular}{|c|c|c|c|c|c|c|}
\hline & Mean RT & $\%$ Error & & & Mean RT & $\%$ Error \\
\hline & \multicolumn{2}{|c|}{ Normal readers $(n=11)$} & \multicolumn{2}{|c|}{ Dyslexics $(n=12)$} & $t(d f=21)$ & \\
\hline \multicolumn{7}{|c|}{ Word targets } \\
\hline Alliterating & 1306 (103) & $3.9(0.8)$ & $1411(69)$ & $7.3(1.5)$ & 0.9 & 2.0 \\
\hline Unrelated & $1287(107)$ & $3.8(1.1)$ & $1415(61)$ & $6.9(1.5)$ & 1.1 & 1.7 \\
\hline Overall & $1296(105)$ & $3.8(0.9)$ & $1413(64)$ & $7.1(1.3)$ & 1.0 & 2.0 \\
\hline \multicolumn{7}{|c|}{ Non-word targets } \\
\hline Alliterating & $1408(96)$ & $3.3(0.8)$ & $1641(69)$ & $9.9(2.1)$ & 2.0 & $3.0^{* *}$ \\
\hline Unrelated & $1423(110)$ & $3.1(0.7)$ & $1581(78)$ & $6.2(1.7)$ & 1.2 & 1.6 \\
\hline Overall & $1415(103)$ & $3.2(0.6)$ & $1611(72)$ & $8.0(1.8)$ & 1.6 & $2.5^{*}$ \\
\hline
\end{tabular}

$* P<0.05$.

$* * P<0.01$ 
main effects of overlap, respectively, $\left(F_{1,21}=22.7, P=0.000\right)$ and $\left(F_{1,21}=8.5, P<0.01\right)$. Finally, in both groups, alliteration significantly reduced the N400 amplitude in both N400 windows, as indicated by main effects of overlap for the N400a window $\left(F_{1,21}=12.8, P<0.005\right)$ and the N400b window $\left(F_{1,21}=5.9, P<0.025\right)$. (a) normal readers

$\mathrm{Fz}$

$\mathrm{Cz}$

$\mathrm{Pz}$

$\mathrm{T} 3$

$\mathrm{T} 4$

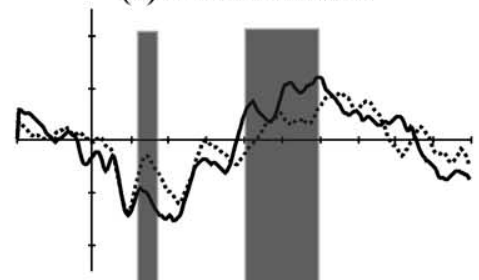

$\mathrm{FCz}$

z
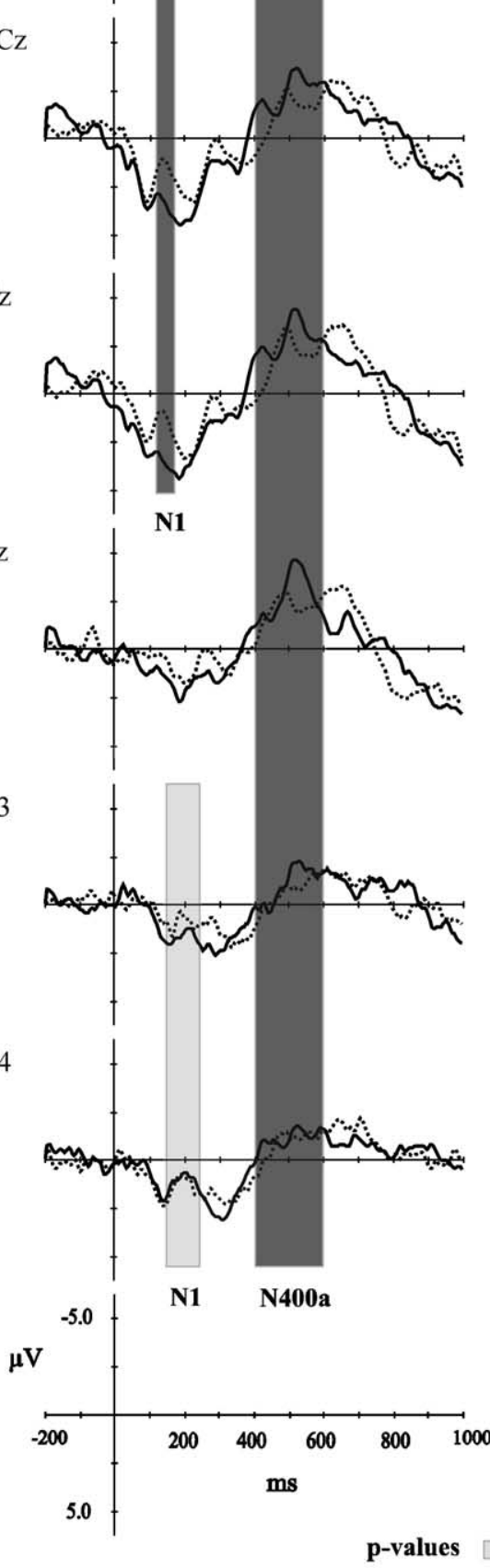

Word Targets

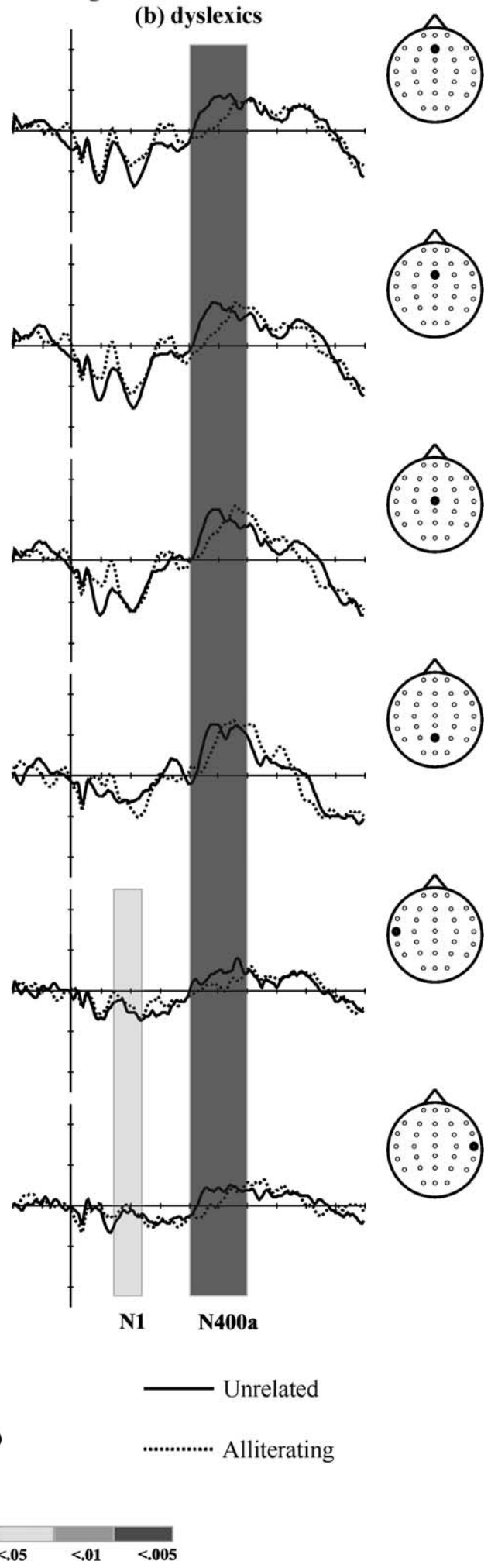

Fig. 5. Grand average ERP waveforms elicited by word targets in Experiment 2 (non-word primes), in (a) normal readers and (b) dyslexics at midline (Fz, FCz, $\mathrm{Cz}, \mathrm{Pz}$ ), left (T3) and right (T4) temporal electrodes. 


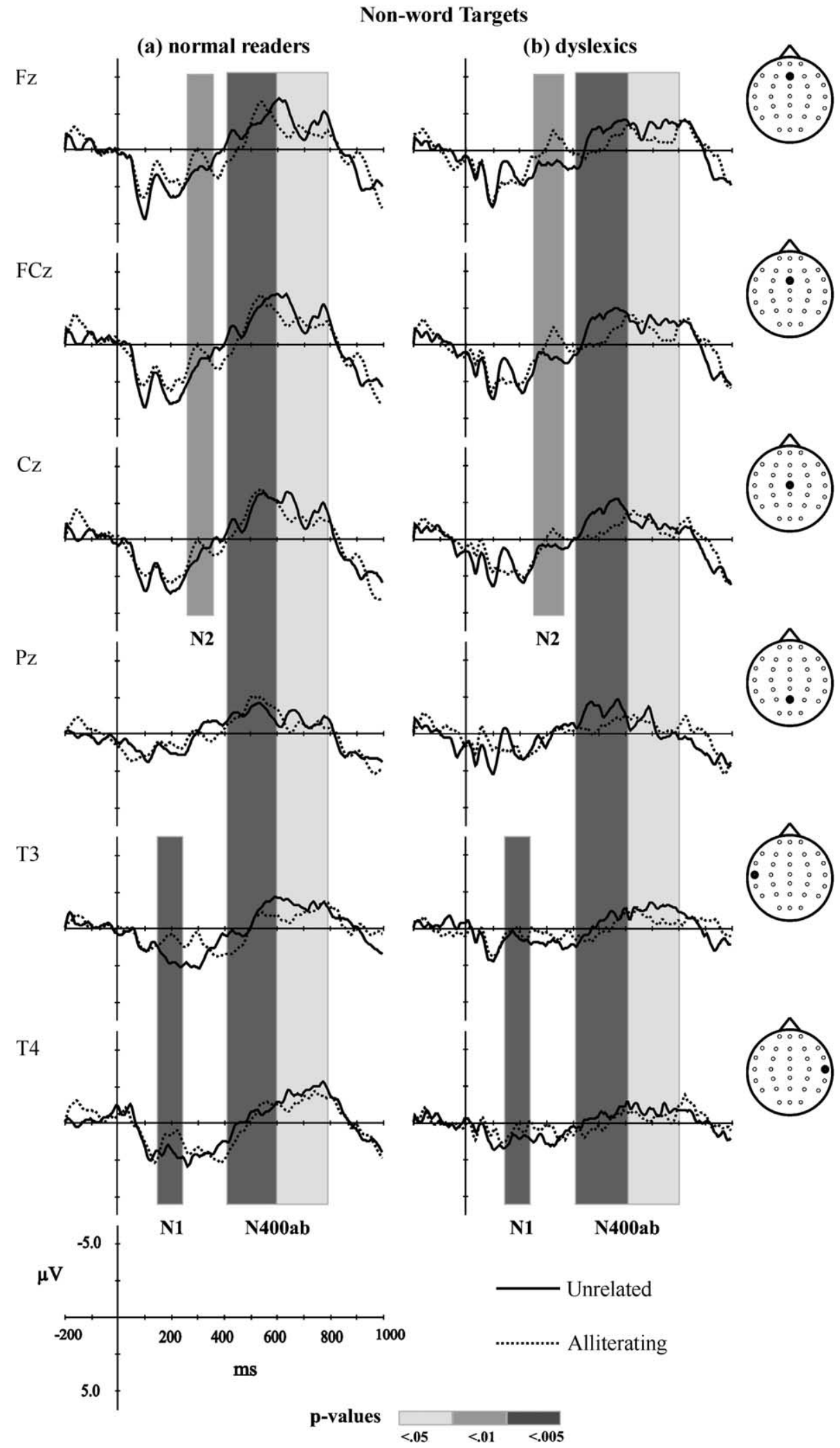

Fig. 6. Grand average ERP waveforms elicited by non-word targets in Experiment 2 (non-word primes), in (a) normal readers and (b) dyslexics at midline (Fz, $\mathrm{FCz}, \mathrm{Cz}, \mathrm{Pz}$ ), left (T3) and right (T4) temporal electrodes. 


\section{Discussion}

We studied ERP correlates of implicit phonological processing (alliteration priming) during spoken word recognition (lexical decision task) in dyslexic and normally reading children. Our ERP findings suggest distinct levels of normal versus anomalous spoken word processing in developmental dyslexia. Whereas dyslexics showed deviant priming effects in earlier time windows encompassing the $\mathrm{N} 1$ and N2, later N400 priming effects were comparable to those of normal readers. The same pattern of results was also shown by group comparisons of general ERP morphology. These findings suggest that, in the absence of phonological task requirements, dyslexics exhibit selective processing anomalies at an earlier phonetic/phonological level, while processing at a later phonological/lexical level proceeds normally.

\subsection{ERPs elicited by word targets}

As little is known about ERPs elicited during spoken word recognition in dyslexic and normally reading children, we first discuss the general pattern of ERPs to word targets in the present experiments. In both groups, word targets elicited a $\mathrm{P} 1-\mathrm{N} 1-\mathrm{P} 2-\mathrm{N} 2-\mathrm{N} 400$ pattern at central electrodes and a $\mathrm{P} 1-\mathrm{N} 1-\mathrm{N} 400$ pattern at lateral electrodes. These ERP patterns are consistent with previous ERP data recorded in children in the same age range with clicks, tones and consonant-vowel stimuli (e.g., Refs. $[12,15,55,72,75])$. Furthermore, our data support the hypothesis that ERP components recorded in children may not simply reflect delayed equivalents of the same components in adults and that especially the N1 and N2 show complex structural and functional changes with age (see also Ref. [7]).

The N1 most likely reflects a pre-cursor of the adult N1 waveform. Probably due to both a relatively long N1 recovery cycle and its overlap with stronger P1 and N2 peaks, the N1 is typically not visible in children when ISIs are shorter than $1 \mathrm{~s}$ (e.g., Refs. [9,12,32]). Moreover, when presenting tones in trains of four with an ISI of $1 \mathrm{~s}$, Karhu et al. [32] did not only find a large decrease in N1 amplitude but also an increase in N2 amplitude upon tone repetition in 9 -year-old children, but not in adults. In contrast to previous developmental ERP studies in which children typically passively listened to repetitive meaningless auditory (speech) stimuli, our children performed active lexical decisions on word and non-word targets. As the N1 amplitude has been found to increase with attention level [44] and linguistic relevance $[65,66]$, the requirements of our experimental task, together with the use of nonrepetitive meaningful stimuli, presumably increased the likelihood of recording the N1 in our children groups. Similar to previous studies that used longer ISIs and measured the $\mathrm{N} 1$ to tones in children, the N1 to word targets was characterized by a prominent negativity at temporal sites and a small amplitude negativity at frontocentral sites, whereas this pattern is typically reversed in adults (e.g., Ref. [9]). Like in adults [18,44], the N1 wave in children has been reported to reflect the activity of several subcomponents each with its own dependence on stimulus parameters, state of the subject and developmental course $[9,51,55]$. Similarly, in the present study, both ERP priming effects and group differences in N1 responses (see below) suggest that the N1 responses measured at fronto-central and lateral sites do not reflect identical aspects of speech processing.

The $\mathrm{N} 2$ measured in our experiments may reflect a typical childhood N2, sometimes called N250, which is the most prominent negativity of the auditory obligatory ERPs in children up to about 10 years of age (e.g., Refs. $[8,12,15,75]$ ). This childhood N2 possibly relates to the adult obligatory "basic" N2 [43] $]^{1}$ and its prominent amplitude in childhood may reflect auditory sensory processing until the efficient adult cortical networks are established [12,75]. The childhood N2 is predominantly recorded at fronto-central sites, which would agree with our findings, and its neural sources have been suggested to include the supratemporal auditory cortex [8]. However, the ERP literature on spoken word recognition in adults offers and alternative explanation for our N2 waveform, that is, in terms of the PMN $[14,26,47,83]$. Because the PMN has been reported in studies involving phonological priming, we will further address this alternative interpretation below, in our discussion of phonological priming effects.

\subsection{Anomalous speech processing in dyslexia: N1 and N2 findings}

Our results indicate that the auditory N1 and N2 as measured in children may not only mark substantial changes in normal development, but may also be particularly relevant in delineating subtle anomalies in speech processing underlying developmental disorders like dyslexia. In particular, we suggest that the group differences in $\mathrm{N} 1$ and N2 morphology indicate a different recruitment of neural sources during speech processing in dyslexic children. Moreover, we suggest that the group differences in N1 and N2 alliteration priming effects imply that these anomalies may relate to phonetic/phonological processing of spoken words.

In the time window encompassing the lateral N1, dyslexics showed significantly smaller ERP amplitudes at temporal electrodes than normal readers. This deviant lateral N1 response may have originated from several functional and/or anatomical anomalies in neural sources involved in speech processing. In adults, the N1 represents an obligatory

\footnotetext{
1 This obligatory N2 differs from other negative components in the same latency range related to attentional processes (the $\mathrm{N} 2 \mathrm{~b}$ ) or soundchange detection (the MMN).
} 
auditory ERP response to any sound onset, with major neural sources in non-primary auditory cortex, e.g., the planum temporale [18]. Planum temporale activity presumably reflects more complex auditory computations than that of the primary auditory cortex [23]. Recent studies suggest, for example, that the planum temporale subserves the processing of phonetic contrasts [30], phonotactic regularity of the native language [30] and the processing of graphemephoneme associations [81]. Similarly, the N1 may selectively respond to the phonetic structure of speech sounds $[19,50,79]$ and to word onsets during the perception of continuous speech $[7,65,66]$. Furthermore, dyslexia has been associated with a deviant planum temporale morphology (see Ref. [25]). Thus, the deviant N1 response as observed in dyslexics in the present study, may indicate a deviant source location (e.g., Ref. [27]) and/or a deviant strength in neural activation (e.g., Refs. [28,29]) of N1 sources involved in similar aspects of speech processing. Although previous behavioral [5,6] and ERP [28,68,69] findings imply that these deviancies may be specific to the processing of speech, our data do not exclude the possibility of more general deviancies in auditory processing, e.g., the discrimination of complex temporal information (e.g., Refs. $[34,45])$.

The effects of alliteration priming on ERPs observed in the present study suggest that some of the group differences between dyslexic and normally reading children may be specifically related to the processing of word onsets. Significant effects of alliteration were found in the N1 window, indicating that phonological priming started to exert its effect already at the level of acoustic or phonetic processing of speech sounds (see Ref. [14] for phonological priming effects at a similar latency). In normal readers, opposite priming effects were observed with word targets in Experiment 1 (word primes), i.e., an N1 reduction with alliteration, and Experiment 2 (non-word primes), i.e., an N1 enhancement with alliteration, suggesting that the processing of word onsets was affected by the lexical status of the primes. These opposite alliteration effects may have resulted from differences in e.g., the time course of word vs. non-word prime processing and/or more general context or expectancy effects with word vs. nonword primes (see also Ref. [7]). In dyslexics, the absence of these alliteration effects at the central N1 with both word and non-word primes, indicates an anomalous contribution of phonetic/phonological (word onset) information to the recognition of spoken words. Because in our previous study both pre-schoolers and adults showed the same pattern of opposite early priming effect as normally reading children, this deviance in dyslexics probably did not result from differences in reading level or a maturational delay.

In the subsequent time window encompassing the N2, dyslexics showed overall larger ERP amplitudes than normal readers. In both experiments, dyslexics and normal readers showed the same N2 amplitude enhancement to alliterating non-word targets. As indicated before, the N2 recorded in the present study may reflect a typical childhood N2, or alternatively a PMN response. Although both alternatives would lead to a similar conclusion in terms of a pre-lexical processing deviancy in dyslexics, the exact interpretation of our N2 findings would be different. So, if the N2 would in fact represent the obligatory auditory N2 component that is typically very robust in children $[8,12,15,75]$, our findings may reflect differences in speech processing that may not be observable when studying adult dyslexics. Previous evidence for the potential importance of the $\mathrm{N} 2$ response as a marker for the development of auditory processing and language acquisition comes from a study, which showed deviant N2 responses in children with language impairment [80]. Although the precise nature of the processes underlying the childhood N2 has still to be elucidated, several possibilities have been suggested in the literature. Karhu et al. [32] found an N2 amplitude increase upon sound repetition in 9-year-old children, but not in adults, and suggested that this amplitude increase may reflect an automatic build-up of neuronal representations in developing networks. Furthermore, the N2 has been related to the processing of sensory stimulus attributes such as acoustical complexity [11]. The increased N2 response to word targets as shown by dyslexics in the present study may thus reflect subtle anomalies in similarly basic aspects of pre-lexical speech processing. The N2 alliteration priming effects observed with non-word targets in both groups in both experiments, indicate that neural sources underlying the N2 may also be involved in speech specific processes.

Alternatively, these alliteration priming effect may support the hypothesis that the $\mathrm{N} 2$ reflects a PMN response $[14,47,83]$. The PMN may be present whenever an experimental task requires phonological processing, and it shows enhanced activity whenever sound-based speech representations do not match a phonological expectation that is build in verbal working memory [16]. Thus, the observed N2 enhancement, rather than the typically reported reduction, elicited by alliterating non-word targets, would imply that alliterating non-word targets initially deviated more from the expected speech input than unrelated nonword targets. This may be due to task-related factors; for example, the auditory lexical decision task may primarily build an expectation for lexicality (i.e., word targets require an affirmative response), rather than for specific word onsets, which is the case in studies that reported PMN effects $[14,16,47,83]$. Along the same line, an PMN interpretation would suggest that the generally enhanced $\mathrm{N} 2$ response to word targets in dyslexics as compared to normal readers reflects a relatively increased effort in accessing phonological representations in working memory [16]. Or, in other words, dyslexics may experience increased processing effort during the translation of acoustic input into pre-lexical phonological representations necessary for lexical access [47]. It is important to note that the two proposed 
interpretations of the $\mathrm{N} 2$ may not be mutually exclusive, that is, in principle the $\mathrm{N} 2$ response may reflect a typical childhood N2, with superimposed PMN effects. Overall, both our $\mathrm{N} 1$ and $\mathrm{N} 2$ results suggest an anomalous contribution of phonological (word onset) information to the processing of spoken words in dyslexic children, which may be related to time-course aspects of pre-lexical phonetic/phonological processing.

\subsection{Comparable N400 priming effects in normal readers and dyslexics}

A main goal of the present study was to investigate ERP measures of phonological processing in dyslexic children without imposing the requirements of an explicit phonological task. Previous ERP studies mainly used phonological awareness tasks, and reported deviant phonological N400 effects in dyslexics (e.g., Refs. [38,39]). Our results indicate that, without such a phonological task, dyslexics may show normal phonological priming effects in the N400 window. In both dyslexics and normal readers, alliteration led to a late N400 amplitude enhancement to word targets preceded by word primes (Experiment 1) and to N400 amplitude reductions in all other conditions. The N400 amplitude reductions due to alliteration are similar to the phonological N400 effects reported in the literature (e.g., Refs. $[13,56])$. Furthermore, our results support the hypothesis that the phonological N400 effect tends to be better detectable without concomitant and effortful semantic processing of words [54]. That is, the N400 amplitude reduction was largest when both primes and targets were non-words and it was clearly smaller when either primes or targets were non-words.

The opposite effect of alliteration when both primes and targets were words, i.e., an N400 amplitude enhancement, as shown by both groups, may reflect specific priming effects at a lexico-phonological level of processing. In both children groups, alliteration also led to significantly longer RTs in this condition. Words sharing onsets are assumed to compete for activation during spoken word recognition [40]. In the present study, this lexical competition process may have resulted in an increased processing effort in case of alliterating word-word pairs in both normally reading and dyslexic children and may explain both the increased RT and the enhanced N400 amplitude. In our previous study, neither pre-schoolers nor adults showed this RT inhibition effect or N400 amplitude enhancement [7]. The presence of these priming effects may thus reflect age-specific characteristics of lexical processing, which are similar for dyslexics and normal readers.

\section{Conclusions}

The present ERP results indicate an anomaly in phonetic/ phonological processing of spoken words in dyslexic children along with normal word processing at a phonological/lexical level. The most prominent deviance in ERP priming effects in dyslexics was the absence of an N1 amplitude reduction to alliterating word-word pairs. This N1 priming effect is present in pre-schoolers, normal readers and adults [7], suggesting a qualitative, age-independent anomaly in phonetic/phonological processing of word onsets in dyslexics. Conversely, the N400 enhancement as shown with alliterating word-word pairs in both subject groups, has not been found in the other age groups [7] and may thus reflect age-specific characteristics of lexical processing, which are similar in dyslexics and normal readers. Furthermore, the finding of normal alliteration priming effects in the N400 window in dyslexics contrasts with previous studies that used explicit phonological awareness tasks. Thus suggesting that deviancies in phonological N400 effects critically depend upon the requirements of an explicit phonological task. Group comparisons of ERP morphology corroborated the pattern of abnormal processing in earlier time windows encompassing the $\mathrm{N} 1$ and $\mathrm{N} 2$, together with normal processing in the later N400 windows. It is important to note that our ERP data do not exclude the possibility of more general differences in complex auditory processing.

In conclusion, the present study explored on-line phonological processing (in)capacities in dyslexic children during spoken word recognition. ERP measures of implicit phonological processing allowed us to distinguish distinct levels of normal versus anomalous processing. In particular, the observed pattern of deviant early versus normal late priming effects in dyslexic children indicates a specific anomaly in the time-course of phonetic/phonological processing of spoken words.

\section{Acknowledgements}

The authors are grateful to the Regionaal Instituut voor Dyslexie (RID), the Basisschool de Kring en St. Aloysius for their support in acquiring subjects. The RID also provided us with the diagnostic data of the dyslexics. In addition, we are grateful to Nadia Zellagui and Hanne Poelmans for assistance in data acquisition, and Elia Formisano and two anonymous reviewers for useful comments on the manuscript.

\section{References}

[1] P.T. Ackerman, R.A. Dykman, D.M. Oglesby, Visual event-related potentials of dyslexic children to rhyming and nonrhyming stimuli, J. Clin. Exp. Neuropsychol. 16 (1994) 138-154.

[2] M. Annett, Family handedness in three generations predicted by the right shift theory, Ann. Hum. Genet. 42 (1979) 479-491.

[3] N. Bleichrodt, P.J.D. Drenth, J.N. Zaal, W.C.M. Resing, Revisie Amsterdamse Kinder Intelligentie Test, Instructie, Normen, Psychometrische Gegevens, Swets \& Zeitlinger, Lisse, 1984. 
[4] L. Blomert, Dyslexie: stand van zaken (Dyslexia: State of Affairs in the Netherlands). Report for the Dutch Ministry of Health, in: R. Reij (Ed.), Dyslexie Naar een vergoedingsregeling, Dutch Health Care Insurance Board, Amstelveen, 2003, pp. publication number 03/144.

[5] L. Blomert, H. Mitterer, The fragile nature of the speech-perception deficit in dyslexia: natural vs synthetic speech, Brain Lang. 89 (2004) $21-26$.

[6] L. Blomert, H. Mitterer, C. Paffen, In search of the auditory, phonetic and/or phonological problems in dyslexia: context effects in speech perception, J. Speech Lang. Hear. Res. (in press).

[7] M. Bonte, L. Blomert, Developmental changes in ERP correlates of spoken word recognition during early school years: a phonological priming study, Clin. Neurophysiol. 115 (2004) 409-423.

[8] N. Bruneau, M. Gomot, Auditory evoked potentials (N1 wave) as indices of cortical development, in: B. Garreau (Ed.), Neuroimaging in Child Neuropsychiatric Disorders, Springer, Berlin, 1998, pp. 113-124.

[9] N. Bruneau, S. Roux, P. Guerin, C. Barthelemy, G. Lelord, Temporal prominence of auditory evoked potentials (N1 wave) in 4-8-year-old children, Psychophysiology 34 (1997) 32-38.

[10] B.T. Brus, M.J.M. Voeten, Een-Minuut-Test, Swets \& Zeitlinger, Lisse, 1999.

[11] R. Ceponiene, A. Shestakova, P. Balan, P. Alku, K. Yiaguchi, R. Naatanen, Children's auditory event-related potentials index sound complexity and "speechness", Int. J. Neurosci. 109 (2001) 245-260.

[12] R. Ceponiene, T. Rinne, R. Naatanen, Maturation of cortical sound processing as indexed by event-related potentials, Clin. Neurophysiol. 113 (2002) 870-882.

[13] D. Coch, G. Grossi, S. Coffey Corina, P.J. Holcomb, H.J. Neville, A developmental investigation of ERP auditory rhyming effects, Dev. Sci. 5 (2002) 467-489.

[14] J.F. Connolly, N.A. Phillips, Event-related potential components reflect phonological and semantic processing of the terminal word of spoken sentences, J. Cogn. Neurosci. 6 (1994) 256-266.

[15] V. Csepe, On the origin and development of the mismatch negativity, Ear Hear 16 (1995) 91-104.

[16] R.C. D'Arcy, J.F. Connolly, E. Service, C.S. Hawco, M.E. Houlihan, Separating phonological and semantic processing in auditory sentence processing: a high-resolution event-related brain potential study, Hum. Brain Mapp. 22 (2004) 40-51.

[17] N. Dumay, A. Benraiss, B. Barriol, C. Colin, M. Radeau, M. Besson, Behavioral and electrophysiological study of phonological priming between bisyllabic spoken words, J. Cogn. Neurosci. 13 (2001) $121-143$.

[18] J.J. Eggermont, C.W. Ponton, The neurophysiology of auditory perception: from single units to evoked potentials, Audiol. Neurootol. 7 (2002) 71-99.

[19] C. Eulitz, E. Diesch, C. Pantev, S. Hampson, T. Elbert, Magnetic and electric brain activity evoked by the processing of tone and vowel stimuli, J. Neurosci. 15 (1995) 2748-2755.

[20] M. Fabiani, G. Gratton, M.G.H. Coles, Event-related brain potentials. Methods, theory, and applications, in: J.T. Cacioppo, L.G. Tassinary, G.G. Berntson (Eds.), Handbook of Psychophysiology, Cambridge Univ. Press, New York, 2000, pp. 53-77.

[21] V.M. Garlock, A.C. Walley, J.L. Metsala, Age-of-acquisition, word frequency, and neighborhood density effects on spoken word recognition by children and adults, J. Mem. Lang. 45 (2001) $468-492$.

[22] M. Ghyselinck, W. de Moor, M. Brysbaert, Age-of-acquisition ratings for 2816 Dutch four- and five-letter nouns, Psychol. Belg. 40 (2000) $77-98$.

[23] T.D. Griffiths, J.D. Warren, The planum temporale as a computational hub, Trends Neurosci. 25 (2002) 348-353.

[24] G. Grossi, D. Coch, S. Coffey Corina, P.J. Holcomb, H.J. Neville, Phonological processing in visual rhyming: a developmental ERP study, J. Cogn. Neurosci. 13 (2001) 610-625.
[25] M. Habib, The neurological basis of developmental dyslexia: an overview and working hypothesis, Brain 123 (Pt. 12) (2000) 2373-2399.

[26] P. Hagoort, C.M. Brown, ERP effects of listening to speech: semantic ERP effects, Neuropsychologia 38 (2000) 1518-1530.

[27] S. Heim, C. Eulitz, T. Elbert, Altered hemispheric asymmetry of auditory $\mathrm{N} 100 \mathrm{~m}$ in adults with developmental dyslexia, NeuroReport 14 (2003) 501-504.

[28] P. Helenius, R. Salmelin, U. Richardson, S. Leinonen, H. Lyytinen, Abnormal auditory cortical activation in dyslexia $100 \mathrm{msec}$ after speech onset, J. Cogn. Neurosci. 14 (2002) 603-617.

[29] P. Helenius, R. Salmelin, E. Service, J.F. Connolly, S. Leinonen, H. Lyytinen, Cortical activation during spoken-word segmentation in nonreading-impaired and dyslexic adults, J. Neurosci. 22 (2002) $2936-2944$

[30] L. Jancke, T. Wustenberg, H. Scheich, H.J. Heinze, Phonetic perception and the temporal cortex, NeuroImage 15 (2002) 733-746.

[31] P.W. Jusczyk, From general to language-specific capacities: the WRAPSA model of how speech perception develops, J. Phon. 21 (1993) 3-28.

[32] J. Karhu, E. Herrgard, A. Paakkonen, L. Luoma, E. Airaksinen, J. Partanen, Dual cerebral processing of elementary auditory input in children, NeuroReport 8 (1997) 1327-1330.

[33] M. Kronbichler, F. Hutzler, H. Wimmer, Dyslexia: verbal impairments in the absence of magnocellular impairments, NeuroReport 13 (2002) $617-620$.

[34] T. Kujala, K. Myllyviita, M. Tervaniemi, K. Alho, J. Kallio, R. Naatanen, Basic auditory dysfunction in dyslexia as demonstrated by brain activity measurements, Psychophysiology 37 (2000) 262-266.

[35] M. Kutas, B.M. Schmitt, Language in microvolts, in: M.T. Banich, M.A. Mack (Eds.), Mind, Brain, and Language: Multidisciplinary Perspectives, Erlbaum Assoc. Lawrence, Mahwah, NJ, USA, 2003, pp. 171-209.

[36] D. Lovrich, J.C. Cheng, D.M. Velting, Late cognitive brain potentials, phonological and semantic classification of spoken words, and reading ability in children, J. Clin. Neuropsychol. 18 (1996) 161-177.

[37] D. Lovrich, J.C. Cheng, D.M. Velting, V. Kazmerski, Auditory ERPs during rhyme and semantic processing: effects of reading ability in college students, J. Clin. Exp. Neuropsychol. 19 (1997) 313-330.

[38] W.B. McPherson, P.T. Ackerman, A study of reading disability using event-related brain potentials elicited during auditory alliteration judgments, Dev. Neuropsychol. 15 (1999) 359-378.

[39] W.B. McPherson, P.T. Ackerman, P.J. Holcomb, R.A. Dykman, Event-related brain potentials elicited during phonological processing differentiate subgroups of reading disabled adolescents, Brain Lang. 62 (1998) 163-185.

[40] J.M. McQueen, A. Cutler, Spoken word access processes: an introduction, Lang. Cogn. Processes 16 (2001) 469-490.

[41] J.L. Metsala, A.C. Walley, Spoken vocabulary growth and the segmental restructuring of lexical representations: precursors to phonemic awareness and early reading ability, in: J.L. Metsala (Ed.), Word Recognition in Beginning Literacy, Lawrence Erlbaum Associates Publishers, Mahwah, NJ, USA, 1998, pp. 89-120.

[42] M. Mody, M. Studdert-Kennedy, S. Brady, Speech perception deficits in poor readers: auditory processing or phonological coding? J. Exp. Child Psychol. 64 (1997) 199-231.

[43] R. Näätänen, T.W. Picton, N2 and automatic versus controlled processes, Electroencephalogr. Clin. Neurophysiol., Suppl. 38 (1986) 169-186.

[44] R. Näätänen, T. Picton, The N1 wave of the human electric and magnetic response to sound: a review and an analysis of the component structure, Psychophysiology 24 (1987) 375-425.

[45] S. Nagarajan, H. Mahncke, T. Salz, P. Tallal, T. Roberts, M.M. Merzenich, Cortical auditory signal processing in poor readers, Proc. Natl. Acad. Sci. U. S. A. 96 (1999) 6483-6488.

[46] National Research Council, Report on Preventing Reading Difficulties in Young Children, National Academy Press, Washington, DC, 1998. 
[47] R.L. Newman, J.F. Connolly, E. Service, K. McIvor, Influence of phonological expectations during a phoneme deletion task: evidence from event-related brain potentials, Psychophysiology 40 (2003) $640-647$

[48] S. Nittrouer, Do temporal processing deficits cause phonological processing problems? J. Speech Lang. Hear Res. 42 (1999) 925-942.

[49] M.R. Nuwer, G. Comi, R. Emerson, A. Fuglsang-Frederiksen, J.M. Guerit, H. Hinrichs, A. Ikeda, F.J. Luccas, P. Rappelsburger, IFCN standards for digital recording of clinical EEG. International Federation of Clinical Neurophysiology, Electroencephalogr. Clin. Neurophysiol. 106 (1998) 259-261.

[50] J. Obleser, A. Lahiri, C. Eulitz, Auditory-evoked magnetic field codes place of articulation in timing and topography around 100 milliseconds post syllable onset, NeuroImage 20 (2003) 1839-1847.

[51] E.W. Pang, M.J. Taylor, Tracking the development of the N1 from age 3 to adulthood: an examination of speech and non-speech stimuli, Clin. Neurophysiol. 111 (2000) 388-397.

[52] B.F. Pennington, The genetics of dyslexia, J. Child Psychol. Psychiatry 31 (1990) 193-201.

[53] C.A. Perfetti, R. Sandak, Reading optimally builds on spoken language: implications for deaf readers, J. Deaf Stud. Deaf Educ. 5 (2000) $32-50$.

[54] F. Perrin, L. Garcia-Larrea, Modulation of the N400 potential during auditory phonological/semantic interaction, Cogn. Brain Res. 17 (2003) 36-47.

[55] C.W. Ponton, J.J. Eggermont, B. Kwong, M. Don, Maturation of human central auditory system activity: evidence from multi-channel evoked potentials, Clin. Neurophysiol. 111 (2000) 220-236.

[56] P. Praamstra, A.S. Meyer, W.J.M. Levelt, Neurophysiological manifestations of phonological processing: latency variations of a negative ERP component timelocked to phonological mismatch, J. Cogn. Neurosci. 6 (1994) 204-219.

[57] M. Radeau, M. Besson, E. Fonteneau, S.L. Castro, Semantic, repetition and rime priming between spoken words: behavioral and electrophysiological evidence, Biol. Psychol. 48 (1998) 183-204.

[58] F. Ramus, Outstanding questions about phonological processing in dyslexia, Dyslexia 7 (2001) 197-216.

[59] F. Ramus, Developmental dyslexia: specific phonological deficit or general sensorimotor dysfunction? Curr. Opin. Neurobiol. 13 (2003) $212-218$.

[60] F. Ramus, S. Rosen, S.C. Dakin, B.L. Day, J.M. Castellote, S. White, U. Frith, Theories of developmental dyslexia: insights from a multiple case study of dyslexic adults, Brain 126 (2003) 841-865.

[61] J. Raven, J.C. Raven, J.H. Court, Coloured Progressive Matrices, 1998 ed., Oxford Psychologists Press, Oxford, 1998.

[62] M.A. Reed, Speech perception and the discrimination of brief auditory cues in reading disabled children, J. Exp. Child Psychol. 48 (1989) $270-292$.

[63] G. Reid Lyon, Toward a definition of dyslexia, Ann. Dyslexia 45 (1995) 3-27.

[64] M.D. Rugg, Event-related potentials and the phonological processing of words and non-words, Neuropsychologia 22 (1984) 435-443.

[65] L.D. Sanders, H.J. Neville, An ERP study of continuous speech processing: I. Segmentation, semantics, and syntax in native speakers, Cogn. Brain Res. 15 (2003) 228-240.
[66] L.D. Sanders, H.J. Neville, An ERP study of continuous speech processing: II. Segmentation, semantics, and syntax in non-native speakers, Cogn. Brain Res. 15 (2003) 214-227.

[67] A. Schaerlaekens, D. Kohnstamm, M. Lejaegere, Streeflijst woordenschat voor zesjarigen, 3rd revised ed., Swets \& Zeitlinger, Lisse, 1999.

[68] G. Schulte-Korne, W. Deimel, J. Bartling, H. Remschmidt, Auditory processing and dyslexia: evidence for a specific speech processing deficit, NeuroReport 9 (1998) 337-340.

[69] G. Schulte-Korne, W. Deimel, J. Bartling, H. Remschmidt, Speech perception deficit in dyslexic adults as measured by mismatch negativity (MMN), Int. J. Psychophysiol. 40 (2001) 77-87.

[70] H.V. Semlitsch, P. Anderer, P. Schuster, O. Presslich, A solution for reliable and valid reduction of ocular artifacts, applied to the P300 ERP, Psychophysiology 23 (1986) 695-703.

[71] W. Serniclaes, L. Sprenger-Charolles, R. Carre, J.F. Demonet, Perceptual discrimination of speech sounds in developmental dyslexia, J. Speech Lang. Hear. Res. 44 (2001) 384-399.

[72] A. Sharma, N. Kraus, T.J. McGee, T.G. Nicol, Developmental changes in $\mathrm{P} 1$ and $\mathrm{N} 1$ central auditory responses elicited by consonant-vowel syllables, Electroencephalogr. Clin. Neurophysiol. 104 (1997) 540-545.

[73] M.J. Snowling, Dyslexia, 2nd edn., Blackwell, Oxford, UK, 2000.

[74] J. Stein, V. Walsh, To see but not to read; the magnocellular theory of dyslexia, Trends Neurosci. 20 (1997) 147-152.

[75] K. Takeshita, T. Nagamine, D.H. Thuy, T. Satow, M. Matsuhashi, J. Yamamoto, M. Takayama, N. Fujiwara, H. Shibasaki, Maturational change of parallel auditory processing in school-aged children revealed by simultaneous recording of magnetic and electric cortical responses, Clin. Neurophysiol. 113 (2002) 1470-1484.

[76] P. Tallal, Auditory temporal perception, phonics, and reading disabilities in children, Brain Lang. 9 (1980) 182-198.

[77] E. Temple, Brain mechanisms in normal and dyslexic readers, Curr. Opin. Neurobiol. 12 (2002) 178-183.

[78] G. Thierry, B. Doyon, J.F. Demonet, ERP mapping in phonological and lexical semantic monitoring tasks: a study complementing previous PET results, NeuroImage 8 (1998) 391-408.

[79] H. Tiitinen, P. Sivonen, P. Alku, J. Virtanen, R. Naatanen, Electromagnetic recordings reveal latency differences in speech and tone processing in humans, Cogn. Brain Res. 8 (1999) 355-363.

[80] I. Tonnquist-Uhlen, Topography of auditory evoked long-latency potentials in children with severe language impairment: the P2 and N2 components, Ear Hear 17 (1996) 314-326.

[81] N. Van Atteveldt, E. Formisano, R. Goebel, L. Blomert, Integration of letters and speech sounds in the human brain, Neuron 43 (2004) $271-282$

[82] K.P. Van den Bos, H.C. lutje Spelberg, A.J.M. Scheepsma, J.R. de Vries, De Klepel, Swets \& Zeitlinger, Lisse, 1999.

[83] D. Van den Brink, C.M. Brown, P. Hagoort, Electrophysiological evidence for early contextual influences during spoken-word recognition: N200 versus N400 effects, J. Cogn. Neurosci. 13 (2001) 967-985.

[84] WISC-R projectgroup: V. Haasen, E.E.J. De Bruyn, Y.J. Pijl, Y.H. Poortinga, H.C. Spelberg, G. Van der Steene, P. Coetsier, R. Spoelders-Claes, J. Stinissen, WISC-R, Nederlandstalige uitgave, Swets \& Zeitlinger, Lisse, 1986. 